\title{
Effects of milk supplementation for one week on the urine proteome in rats
}

\begin{abstract}
Urine is a good source of disease biomarkers. However, urine composition can be affected by many physiological factors. In this study, urinary proteins of rats fed with milk were analyzed by LC-MS/MS to discover the effects of milk supplementation on the urine proteome. Compared with the control group, only the major urinary protein was increased in all six rats, and four proteins were found to differ in five of six rats in the milk-fed group. These results suggest that the urinary proteome tends to remain in a largely stable state when the rats are fed milk for one week instead of water based on shotgun protein identification and the label-free quantitation.
\end{abstract}

Keywords: urine proteome, influence factor, milk supplementation
Volume 7 Issue I - 2018

\author{
Manxia An,' Jianqiang Wu, 'Yanying Ni,' Youhe \\ Gao, \\ 'Department of Pathophysiology, Institute of Basic Medical \\ Sciences Chinese Academy of Medical Sciences, China \\ ${ }^{2}$ Department of Biochemistry and Molecular Biology, Beijing \\ Normal University, China
}

Correspondence: Department of Biochemistry and Molecular Biology, Gene Engineering Drug and Biotechnology Beijing Key Laboratory, Beijing Normal University, Beijing, 100875, China Email gaoyouhe@bnu.edu.cn

Received: January 23, 2018 | Published: January 30, 2018

\section{Introduction}

Biomarkers are the measurable changes associated with a physiological or pathophysiological process. ${ }^{1}$ Because urine is not subject to the control of homeostatic mechanisms, its composition undergoes many changes; thus, urine may represent a good source of biomarkers. Urinary analysis has been used in a variety of disease biomarker studies. ${ }^{2-5}$ Studies have shown that changes caused by anticoagulants and short diet interventions can be more easily detected in urine than blood. ${ }^{6,7}$ However, urine is sensitive to a number of factors; many physiological parameters, including age, gender, lifestyle, and hormones, can cause changes to urine. ${ }^{8-12}$ Changes caused by these factors may interfere with disease-related changes in disease biomarker studies. Whether identified biomarkers directly relate to a disease itself or to confounding factors may be unclear. The effects of physiological factors are more significant in the early stages of disease. Changes in urine caused by early-stage disease are relatively minor, and these changes are more likely to be interfered. Therefore, assessing and sorting out the effects of confounding factors on urine is essential to the discovery of disease markers that are more specific and reliable.

As one of the most common foods for humans, milk is consumed as a nutritional supplement worldwide. Milk contains abundant functional components, including protein, fat, vitamins, and a variety of minerals that are essential for growth and development. ${ }^{13}$ However, the effect of milk supplementation on urinary proteins has not been studied.

In this study, the urinary proteomes of rats fed milk for one week were analyzed by shotgun LC-MS/MS to investigate the short-term effects of milk supplementation on the urine proteome in rats.

\section{Materials and methods}

\section{Animal experiments}

Male Sprague-Dawley rats $(160-180 \mathrm{~g})$ were purchased from the Institute of Experimental Animals of the Chinese Academy of Medical Sciences. All rats were housed in a standard environment (temperature: $22 \pm 1{ }^{\circ} \mathrm{C}$; humidity: $65 \%-70 \%$ ) and had free access to diet and water. The animal experiments were approved by the Institute of Basic Medical Sciences Animal Ethics Committee, Peking Union Medical College (Animal Welfare Assurance Number: ACUC-A02-2013-015).

The rats were divided into 2 groups: a control group $(\mathrm{n}=8)$ and a milk-fed group $(n=8)$. Every four rats were housed in a cage. The control group rats were given free access to water and were not provided with milk. The milk-fed group rats were given free access to milk and were not provided with water. Food intake, water intake and weight gain were recorded daily. Urine samples were collected after 1 week and stored at $-80^{\circ} \mathrm{C}$. Protein and creatinine concentrations in the urine were measured at the Beijing Union Medical College Hospital.

\section{Urinary protein extraction}

Urine was centrifuged at $2,000 \mathrm{~g}$ for $20 \mathrm{~min}$ to remove cell debris, and the supernatant was then centrifuged at $12,000 \mathrm{~g}$ for $20 \mathrm{~min}$; the supernatant was transferred to a new tube. Three volumes of absolute acetone were added to the supernatant, which was then precipitated at $-20^{\circ} \mathrm{C}$ overnight. ${ }^{14}$ The pellet was re-dissolved in lysis buffer (8M urea, 2M thiourea, $25 \mathrm{mM}$ dithiothreitol and $50 \mathrm{mM}$ Tris). The Bradford method was used for protein quantification.

\section{SDS-PAGE analysis}

A total of $20 \mu \mathrm{g}$ of protein was suspended in sample loading buffer and then incubated at $96^{\circ} \mathrm{C}$ for $5 \mathrm{~min}$. The proteins were separated in SDS-PAGE. The gel was stained with Coomassie brilliant blue dye.

\section{Protein digestion and LC-MS/MS analysis}

The filter-aided sample preparation method was used to digest proteins using trypsin as follows. ${ }^{15}$ A total of $100 \mu \mathrm{g}$ of protein was loaded on to a $10-\mathrm{kDa}$ filter membrane (Pall, Port Washington, NY, USA). The bound proteins were then successively washed with UA (8M urea and $0.1 \mathrm{M}$ Tris- $\mathrm{HCl}, \mathrm{pH} 8.6)$ and ammonium bicarbonate by centrifugation at $14,000 \mathrm{~g}$ for $40 \mathrm{~min}$ at $18^{\circ} \mathrm{C}$. The proteins were reduced by incubation in $20 \mathrm{mM}$ dithiothreitol at $37^{\circ} \mathrm{C}$ for $1 \mathrm{~h}$ and then 
alkylated in the dark for $40 \mathrm{~min}$ using $50 \mathrm{mM}$ iodoacetamide. Next, trypsin (Trypsin Gold, Mass Spec Grade, Promega, Fitchburg, WI, USA) was added to the membrane at an enzyme-to-protein ratio of $1: 50$, and the membrane was incubated at $37^{\circ} \mathrm{C}$ for $13 \mathrm{~h}$. The digested peptides were collected by centrifugation at $14,000 \mathrm{~g}$ for $20 \mathrm{~min}$, and $500 \mathrm{mM}$ sodium chloride was used to elute the residual peptides at $14,000 \mathrm{~g}$ for $20 \mathrm{~min}$. The eluted peptides were then desalted with Oasis HLB cartridges (Waters, Milford, MA, USA) and dried by vacuum evaporation.

One microgram of peptides was loaded onto a reversed-phase microcapillary column by EASY-nLC 1200 UHPLC system. The peptides were eluted with a gradient of $5-28 \%$ mobile phase B $(0.1 \%$ formic acid and $99.9 \%$ acetonitrile; flow rate of $0.3 \mathrm{ml} / \mathrm{min}$ ) for $60 \mathrm{~min}$. The eluted peptides were analyzed using a Thermo Orbitrap Fusion Lumos MS (Thermo Fisher Scientific, Bremen, Germany). Each sample was analyzed in triplicate.

\section{MS data analysis}

The raw files were imported into Progenesis software (version 4.1, Nonlinear, Newcastle upon Tyne, UK) for feature detection, alignment and quantification. ${ }^{16}$ All sample features were aligned based on a reference sample that was automatically selected by the software, and the features with 2, 3 and 4 charges were selected for subsequent analyses. The samples were divided into the control group and the milk-fed group. All features were then exported into an MGF file. The MGF file was loaded into Mascot software (version 2.5.1, Matrix Science, London, UK) and retrieved by the Swissprot_2014_07 database (taxonomy: Rattus). Trypsin was selected as the enzyme and the number of missed trypsin cleavage sites was set to no more than 2. The carbamidomethylation of cysteines was selected as a fixed modification. The fragment mass tolerance and the parent mass tolerance were set to $0.6 \mathrm{Da}$ and $10 \mathrm{ppm}$, respectively. The search results were exported as an XML file. The XML files were reimported into Progenesis software, and proteins identified with only one peptide were not included in the subsequent quantitative analyses.

\section{Results and discussion}

\section{Food intake and water/milk intake}

The average milk intake of the rats (the average is $60 \mathrm{ml}$ ) in the milk-fed group was greater than the average water intake of the rats (the average is $46 \mathrm{ml}$ ) in the control group, while the rats in the control group had a higher average food intake (the average is $29 \mathrm{~g}$ ) than the rats in the milk-fed group (the average is $16 \mathrm{~g}$ ). These trends could be observed during each day of the experiment.

\section{Weight gain and urine protein-to-creatinine ratio}

The milk-fed group showed slightly higher weight gain than the control group, but this difference was not statistically significant (Figure 1). The urine protein-to-creatinine ratio of the rats in the milkfed group was significantly higher than that of the rats in the control group (Figure 2), suggesting that urinary protein excretion in rats increases after milk intake. ${ }^{17}$

\section{SDS-PAGE analysis}

No bands with consistent differences between the milk-fed and the control groups were observed in the SDS-PAGE analysis (Figure 3).

\section{Urinary proteome changes with milk supplementation}

Twelve urine samples from 6 rats in the control group and 6 rats in the milk-fed group were analyzed by LC-MS/MS. Three technical replicates of each sample were analyzed by LC-MS/MS. Progenesis software was used to conduct label-free quantitative analysis. The abundance for each protein was calculated based on the mean abundance of the proteins from 3 replicates. Proteins with significant changes between the control group and the milk-fed group were identified by the following criteria: (1) $\mathrm{P}$ value by ANOVA $<0.05$, (2) fold change $>1.5$, (3) spectral count for each sample $\geq 5$ in at least one group.

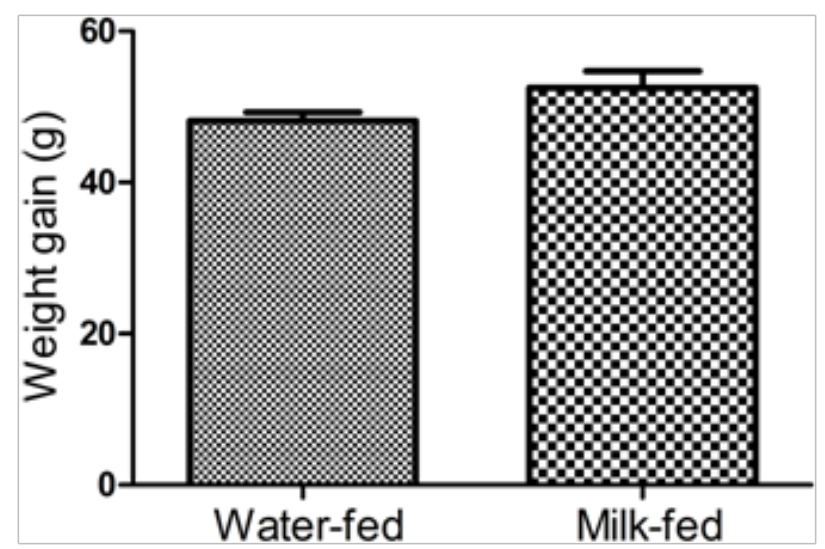

Figure I Weight gain and urine protein-to-creatinine ratio.

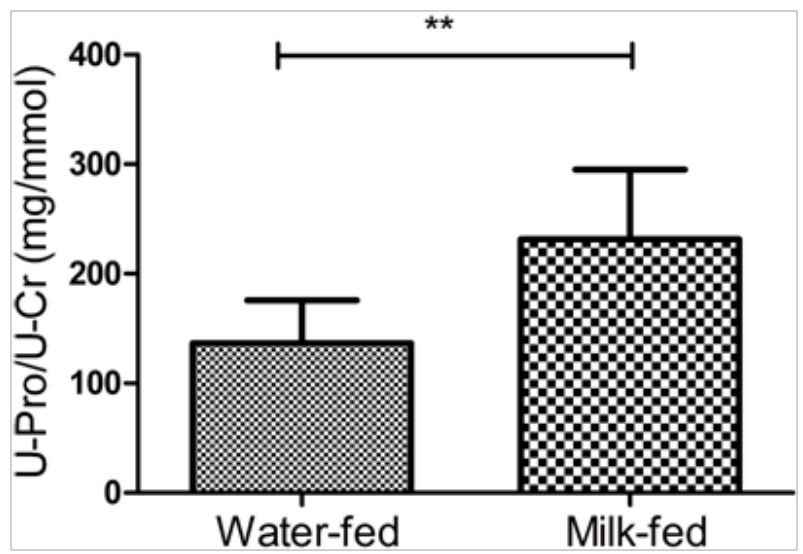

Figure 2 The urine protein-to-creatinine ratio of the rats in the milk-fed group.

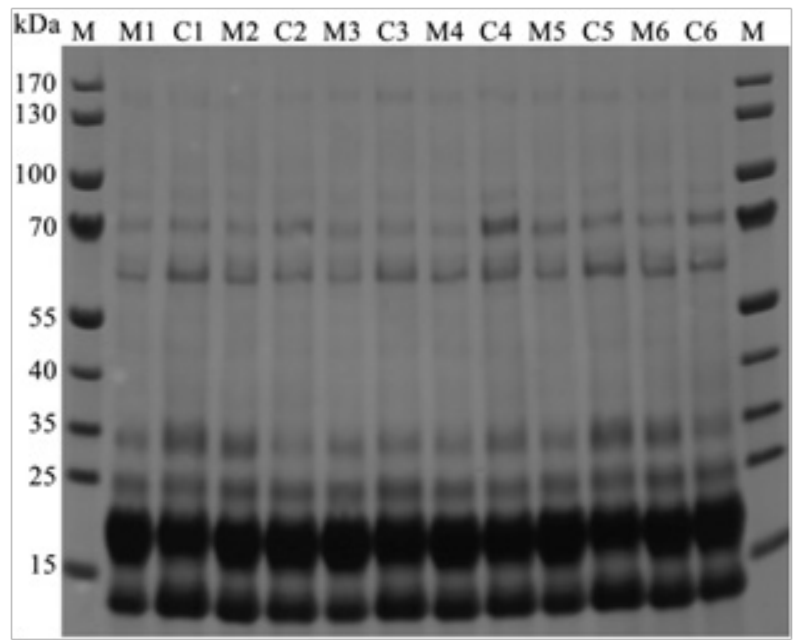

Figure 3 SDS-PAGE analysis. 
A total of 331 proteins were identified in control group and milkfed group (Table 1). According to these criteria, compared with the control group, in the milk-fed group, only the major urinary protein, which has no human orthologs, was increased by 2 -fold in all six rats, and four proteins, including the major urinary protein, were found to differ in five of the six rats (the peak intensities of at least 5 rats in the increased group were greater than the maximal peak intensity of the reduced group or the peak intensities of at least 5 rats in the reduced group were less than the minimal peak intensity of the increased groups). The other three proteins were the neutral and basic amino acid transport protein rBAT, urokinase-type plasminogen activator and corticosteroid-binding globulin, which have human homologs. The levels of these three proteins changed from $0.56-$ to 1.67-fold. Major urinary protein and neutral and basic amino acid transport protein $\mathrm{rBAT}$ increased in the milk-fed group compared to the control group, whereas urokinase-type plasminogen activator and corticosteroid-binding globulin decreased in the milk-fed group compared to the control group. Moreover, neutral and basic amino acid transport protein $\mathrm{rBAT}$ was reported to be a candidate biomarker of sodium loading ${ }^{18}$ and urokinase-type plasminogen activator was reported to be a candidate biomarker of Fanconi syndrome. ${ }^{19}$

Table I The differential proteins changed between control group and milk-fed group. Fold change is milk-fed group-to-control group ratio

\begin{tabular}{|c|c|c|c|c|c|}
\hline Protein name & $\begin{array}{l}\text { Accession } \\
\text { number }\end{array}$ & $\begin{array}{l}\text { Fold- } \\
\text { change }\end{array}$ & $\begin{array}{l}P \\
\text { value }\end{array}$ & Biomarker & Human ensembl gene ID \\
\hline Major urinary protein & MUP_RAT & 2 & 0.002 & No & No \\
\hline Neutral and basic amino acid transport protein rBAT & SLC3I_RAT & 1.68 & 0.004 & Sodium loading & ENSG00000I 38079 \\
\hline Urokinase-type plasminogen activator & UROK_RAT & 0.65 & 0.004 & $\begin{array}{l}\text { Fanconi } \\
\text { syndrome }\end{array}$ & ENSG00000 I $2286 \mathrm{I}$ \\
\hline
\end{tabular}

\section{Conclusion}

In this study, we used 1.5 -fold change as the cutoff, which is a less restrictive standard. Most other biomarker discovery studies use conditions that are more stringent. Under this condition, the milk-related changes may not significantly interfere with biomarker discovery using current identification and quantification techniques. As protein identification and quantification techniques are further developed, additional proteins whose levels are affected by milk may be identified.

It remains to be elucidated why there was a very significant change in Up/Ucr quantity but no significant protein changes in term of species and composition when the samples were analyzed by shotgun LCMS/MS. In addition, the effect of milk feeding for a long-term period may differ from that over a short-term period. In conclusion, milk feeding for one week does not have a great impact on the expression of urinary proteins in rats based on the shotgun protein identification and quantification techniques used in this study.

\section{Acknowledgements}

National Key Research and Development Program of China (2016 YFC 1306300), Beijing Natural Science Foundation (7173264, 7172076), Beijing cooperative construction project (110651103) Beijing Normal University (11100704) Peking Union Medical College Hospital (2016-2.27).

\section{Conflict of interest}

The author(s) declare(s) that there is no conflict of interest regarding the publication of this article.

\section{References}

1. Gao Y. Urine-an untapped goldmine for biomarker discovery? Sci China Life Sci. 2013;56(12):1145-1146.

2. Delles C, Diez J, Dominiczak AF. Urinary proteomics in cardiovascular disease: Achievements, limits and hopes. Proteomics Clin Appl. 2011;5(5-6):222-232.
3. Pejcic M, Stojnev S, Stefanovic V. Urinary proteomics - a tool for biomarker discovery. Ren Fail. 2010;32(2):259-268.

4. Sarosiek I, Schicho R, Blandon P, et al. Urinary metabolites as noninvasive biomarkers of gastrointestinal diseases: A clinical review. World J Gastrointest Oncol. 2016;8(5):459-465.

5. Trovato FM, Tognarelli JM, Crossey MM, et al. Challenges of liver cancer: Future emerging tools in imaging and urinary biomarkers. World J Hepatol. 2015;7(26):2664-2675.

6. Bertram HC, Hoppe C, Petersen BO, et al. An NMR-based metabonomic investigation on effects of milk and meat protein diets given to 8-yearold boys. Br J Nutr. 2007;97(4):758-763.

7. Li M, Zhao M, Gao Y. Changes of proteins induced by anticoagulants can be more sensitively detected in urine than in plasma. Sci China Life Sci. 2014;57(7):649-656.

8. Alfadda AA, Turjoman AA, Moustafa AS, et al. A proteomic analysis of excreted and circulating proteins from obese patients following two different weight-loss strategies. Exp Biol Med (Maywood). 2014;239(5):568-580.

9. Castagna A, Olivieri O, Milli A, et al. Female urinary proteomics: New insight into exogenous and physiological hormone-dependent changes. Proteomics Clin Appl. 2011;5(5-6):343-353.

10. Wu J, Gao Y. Physiological conditions can be reflected in human urine proteome and metabolome. Expert Rev Proteomics. 2015;12(6):623-636.

11. Zheng H, Yde CC, Arnberg K. NMR-based metabolomic profiling of overweight adolescents: an elucidation of the effects of inter-/ intraindividual differences, gender, and pubertal development. Biomed Res Int. 2005;2014:537157.

12. Zurbig P, Decramer S, Dakna M, et al. The human urinary proteome reveals high similarity between kidney aging and chronic kidney disease. Proteomics. 2009;9(8):2108-2117.

13. Pereira PC. Milk nutritional composition and its role in human health. Nutrition. 2014;30(6):619-627.

14. Sun W, Li F, Wu S, et al. Human urine proteome analysis by three separation approaches. Proteomics. 2005;5(18):4994-5001. 
15. Wisniewski JR, Zougman A, Nagaraj N, et al. Universal sample preparation method for proteome analysis. Nat Methods. 2009;6(5):359 362.

16. Hauck SM, Dietter J, Kramer RL, et al. Deciphering membraneassociated molecular processes in target tissue of autoimmune uveitis by label-free quantitative mass spectrometry. Mol Cell Proteomics. 2010;9(10):2292-2305.

17. Price CP, Newall RG, Boyd JC. Use of protein: creatinine ratio measurements on random urine samples for prediction of significant proteinuria: a systematic review. Clin Chem. 2005;51(9):1577-1586.
18. Thongboonkerd V, Klein JB, Pierce WM, et al. Sodium loading changes urinary protein excretion: a proteomic analysis. Am J Physiol Renal Physiol. 2003;284(6):F1155-F1163.

19. Cutillas PR, Chalkley RJ, Hansen $\mathrm{KC}$, et al. The urinary proteome in Fanconi syndrome implies specificity in the reabsorption of proteins by renal proximal tubule cells. Am J Physiol Renal Physiol. 2004;287(3):F353-F364. 